\title{
PREDICTORS OF ENVIRONMENTAL EXPOSURE TO POLYCYCLIC AROMATIC HYDROCARBONS AMONG PREGNANT WOMEN - PROSPECTIVE COHORT STUDY IN POLAND
}

\section{KINGA POLAŃSKA ${ }^{1}$, WOJCIECH HANKE ${ }^{1,2}$, WOJCIECH SOBALA ${ }^{1}$, SŁAWOMIR BRZEŹNICKI ${ }^{3}$ and DANUTA LIGOCKA ${ }^{3}$}

${ }^{1}$ Nofer Institute of Occupational Medicine, Łódź, Poland

Department of Environmental Epidemiology

${ }^{2}$ Medical University, Łódź, Poland

Department of Informatics and Medical Statistics

${ }^{3}$ Nofer Institute of Occupational Medicine, Łódź, Poland

Chemical Safety Department

\begin{abstract}
Objectives: The aim of the study was to characterize the PAH exposure level based on 1-hydroxypyrene (1-HP) in urine of Polish pregnant women and to assess the relationship between PAH and factors such as smoking, environmental tobacco smoke exposure, place of residence, heating and cooking method. Materials and Methods: The study population included in this analysis consisted of 449 pregnant women who had been the subjects of the prospective Polish Mother and Child Cohort study performed in 8 regions of Poland. The women were interviewed three times during pregnancy (once in each trimester). 1-HP concentration in urine was chosen as the biomarker of exposure to PAH. The urine sample was analysed using high performance liquid chromatography (HPLC). The active and passive smoking exposure was verified by saliva cotinine, analysed by high performance liquid chromatography coupled with tandem mass spectrometry (LC-MSMS) and isotope dilution method. Results: 1-HP concentration in urine ranged from 0.02 to $10.2 \mu \mathrm{g} / \mathrm{g}$ creatinine with the geometric mean (GM) $0.4 \mu \mathrm{g} / \mathrm{g}$ creatinine. The significantly higher concentration of urinary 1-HP in pregnant women was observed for summer collection (GM ratio: 1.1; $\mathrm{p}=0.01$ ), among smokers (GM ratio: 1.7; $\mathrm{p}<0.001$ ) and for the women living in big cities (GM ratio: 1.3; $\mathrm{p}=0.001$ ). Conclusions: The significantly higher concentration of urinary 1-HP in pregnant women was observed for summer collection, among smokers and those living in big cities.
\end{abstract}

Key words:

Polycyclic aromatic hydrocarbons, 1-hydroxypyrene, Smoking, Pregnancy

This study was performed under the project "Epidemiology of reproductive hazards in Poland - multicentre, prospective cohort studies" supported by the National Center for Research and Development, Poland; grant no. PBZ-MEiN-/8/2//2006; contract no. K140/P01/2007/1.3.1.1. and K140/P01/2007/2.1.1.

Received: June 30, 2010. Accepted: September 7, 2010.

Address reprint request to K. Polańska, Department of Environmental Epidemiology, Nofer Institute of Occupational Medicine, św. Teresy 8, 91-348 Łódź, Poland (e-mail: kinga@imp.lodz.pl). 


\section{INTRODUCTION}

Polycyclic aromatic hydrocarbons (PAH) are a group of compounds, comprising two or more fused aromatic rings, that are formed as a result of incomplete combustion of organic matter. Sources of environmental contamination can be both industrial and nonindustrial, the most common sources being cigarette smoke, grilled and smoked food processes, coal-fired utilities, steel plants, coke-oven plants, graphite electrode manufacturing plants, Söderberg aluminium electrolysis plants, vehicle exhaust, woodburning ovens and fireplaces.

Because PAH exposure occurs as an exposure to mixture of compounds, pyrene and its main metabolite, 1-hydroxypyrene (1-HP), are considered appropriate surrogate markers of total PAH exposure. The level of this biomarker can be assessed in urine. Complete urine collection may be difficult to achieve due to forgetfulness, misplacement of samples, insufficient container capacity, erroneous inclusion of urine from the first void, or loss of urine during defecation. Furthermore, it may be inconvenient for individuals performing their routine activities to carry containers of urine; this certainly acts to reduce the number of people participating in the study. Thus, the easiest and more convenient way is to collect smaller volumes and combine the biomarker measurement with the determination of creatinine - a measure of diuresis [1]. Smoking is the major source for PAH exposure for subjects not occupationally exposed to PAH, so in the studies evaluating the impact of such exposure (relating to ambient air pollution) on pregnancy outcome, verification of smoking status in pregnancy period seems to be the standard. Smokers excreted significantly higher amounts of 1-HP compared to non-smokers and the number of cigarettes smoked correlated rather well with urinary 1-HP concentration [1-3].

In the case of low environmental exposure to $\mathrm{PAH}$, the consumption of PAH-rich diet (especially grilled, fried and smoked) can influence the excretion of 1-HP, but when the exposure from other sources is important, the contribution of the dietary intakes to the overall exposure is negligible [4,5]. Ambient air pollution levels are related to the industry in the area, intensity of traffic, amount and sources of residential heating and meteorological conditions.

The published data evaluated the PAH exposure among pregnant women mostly based on personal air monitoring or PAH-DNA adduct levels. Detailed analysis of environmental exposure to PAH derived from US and Polish cohorts of pregnant women shows that personal PAH exposure was 10-fold higher in Kraków than in New York City (NYC) (average: $39.1 \mathrm{ng} / \mathrm{m}^{3}$; range: $1.8-272.2 \mathrm{ng} / \mathrm{m}^{3}$ for Kraków women vs. $3.3 \mathrm{ng} / \mathrm{m}^{3}$, range: $0.5-22.1 \mathrm{ng} / \mathrm{m}^{3}$ for NYC African Americans and $3.7 \mathrm{ng} / \mathrm{m}^{3}$; range: $0.3-36.5 \mathrm{ng} / \mathrm{m}^{3}$ for NYC Dominicans) [6].

The studies have indicated that diesel fuel combustion contributes to ambient PAH in NYC, whereas coal burning in small furnaces is a major source of PAH in Kraków [7,8]. The analysis of the predictors of personal PAH exposures was performed by Tonne et al. [7]. In that study the personal exposure of 344 women from NYC ranged from $0.06 \mathrm{ng} / \mathrm{m}^{3}$ for dibenz $[a, h]$ anthracene (DahA) to $4.1 \mathrm{ng} / \mathrm{m}^{3}$ for pyrene. Mean BaP concentration was $0.5 \mathrm{ng} / \mathrm{m}^{3}$. Multiple linear regression analysis revealed association between personal PAH exposure and several variables, including seasonal effect, time spent outdoors, residential heating and indoor burning of incense.

The additional analysis performed in Kraków indicated that the nine analysed PAH and $\Sigma 8 \mathrm{c}-\mathrm{PAH}$ personal indoor, and outdoor levels were more than 10-fold higher in winter than summer [9]. The outdoor PAH level alone accounts for $93 \%$ of total variability in personal exposure during heating season. During the nonheating season a 1-hr increase in environmental tobacco smoke (ETS) exposure was associated with 10-16\% increase in personal exposure to $\mathrm{PAH}$ and $1{ }^{\circ} \mathrm{C}$ decrease in ambient temperature was associated with $3-5 \%$ increase in 
exposure to benz $[a]$ anthracene, benzo $[k]$ fluoranthene and dibenz $[a h]$ anthracene after accounting for the outdoor concentration.

An interesting comparison of the levels of BaP-DNA adducts measured in maternal blood and newborn cord blood in four different populations representing a 30-fold range of exposure to ambient $\mathrm{PAH}$ was performed by Perera et al. [10]. Based on that analysis, the mean concentrations of adducts in both maternal and cord blood and the proportion of samples with detectable adducts increase across the populations consistent with the trend in estimated ambient exposure to PAH $(\mathrm{p}<0.001)$. Jędrychowski et al. indicated that the concentrations of PAH compounds were considerably higher among the residents of the more polluted area of the city [8]. The comparison between the Kraków and NYC demonstrates that not only concentrations but also proportions of specific compounds in the total PAH mixture differ widely across the cities.

The aim of the study was to characterize the PAH exposure level based on 1-HP in urine of Polish pregnant women and to assess the relationship between PAH and factors such as smoking, ETS exposure, place of residence, heating and cooking method.

\section{MATERIAL AND METHODS}

\section{Study design and sample}

The complete description of the cohort and study design was published elsewhere [11]. The study was performed in 8 regions of Poland. The recruitment and all scheduled visits were conducted in maternity units or clinics of the regions participating in the study. The study population included in analysis of predictors of exposure to $\mathrm{PAH}$ consisted of 449 pregnant women. Additionally the comparison of the level of 1-HP in urine collected during the second and third trimester of pregnancy was performed for 217 women.

\section{Inclusion criteria}

The inclusion criteria specified in study protocol were as follows: single pregnancy (up to 12 weeks of gestation), not assisted with reproductive technology and not expected to be finished as spontaneous abortion. All women with the serious chronic diseases specified in study protocol were excluded from the study.

\section{Questionnaires}

All women participating in the study were interviewed by gynecologist/midwife once in each trimester. Any changes in behaviour patterns (i.e. smoking or ETS exposure, changes of place of residence) throughout the pregnancy were noted. The following information was collected: socio-demographic characteristic (age, marital status, number of children, educational level, employment status), previous and current pregnancies, lifestyle exposures including smoking and ETS exposure, alcohol consumption and food frequency questionnaire. Detailed information was also collected about place of residence, heating and cooking methods.

The analysis of the questionnaire data was restricted to the factors that potentially contribute to the exposure to PAH, including smoking status verified by cotinine level in saliva, dietary intake of PAH (frequency of intake of grilled, smoked or fried food), type of heating and cooking method, place of residence (city size measured by number of inhabitants) and season of 1-HP collection (summer season: May-Aug, and winter season: Sep-April).

\section{Exposure variables}

Exposure to PAH

1-HP concentration in urine sample was chosen as the biomarker of exposure to PAH. The urine sample was collected from the women participating in the study between 20-24 weeks of pregnancy and, for some part of the study population, repeated during 30-34 week of pregnancy. The 1-HP was analysed using high performance liquid chromatography (HPLC). 
The analytical procedure used in this study was based on the method described by Jongeneelen et al. [12]. Urine samples $(10 \mathrm{ml})$ were adjusted to $\mathrm{pH}=5.0$ with $1.0 \mathrm{M} \mathrm{HCl}$, buffered with $5 \mathrm{ml}$ of $0.1 \mathrm{M}$ acetate buffer $(\mathrm{pH}=5.0$ ), and incubated for $16 \mathrm{~h}$ with $1500 \mathrm{U} \beta$-glucuronidasearylsulfatase (Sigma-Aldrich) in a shaking bath at $37^{\circ} \mathrm{C}$. 1-HP was concentrated by solid phase extraction on a C-18, $100 \mathrm{mg}$ cartridge (J.T. Baker). Cartridges were conditioned with $5 \mathrm{ml}$ of water and $10 \mathrm{ml}$ of methanol and finally $10 \mathrm{ml}$ of the urine sample was passed trough the cartridge. Cartridge was cleaned by $5 \mathrm{ml}$ of water and dried with vacuum. 1-HP was eluted using $10 \mathrm{ml}$ of methanol. Solvent was evaporated to dryness by heating at $40^{\circ} \mathrm{C}$ under gentle stream of nitrogen. The residue was dissolved in $1 \mathrm{ml}$ of methanol and transferred via syringe filter (PTFE 0,45 $\mu \mathrm{m}$ ) to autosampler vial.

Standards of 1-HP were prepared by spiking of non-smoker urine with methanolic solution of 1-HP to obtain the final concentrations ranging from 0 to $5.0 \mu \mathrm{g} / \mathrm{l}$. 1-HP standards in urine were subjected to the analytical procedures designed for urine samples.

The determinations were made using a Waters Alliance liquid chromatograph equipped with quaternary pump, autosampler, degasser, column oven and Waters 2475 fluorimetric detector. The chromatographic analysis was carried out on a Supelcosil LC-18 $(150 \times 3 \mathrm{~mm})$ column which was eluted with a methanol:water (7:3) mixture at $0.4 \mathrm{ml} / \mathrm{min}$ flow rate. The fluorimetric detector was programmed to operate at 242 and $388 \mathrm{~nm}$ excitation and emission wavelengths, respectively.

Detector response to the calibration standards was linear in the whole concentration range $(r=0.998, \mathrm{RSD}=5 \%)$. The sensitivity of the method is estimated to be $0.2 \mu \mathrm{g} / \mathrm{l}$. An example of chromatographic separation of internal standard of 1-HP and analysed urine sample is presented in Figure 1.

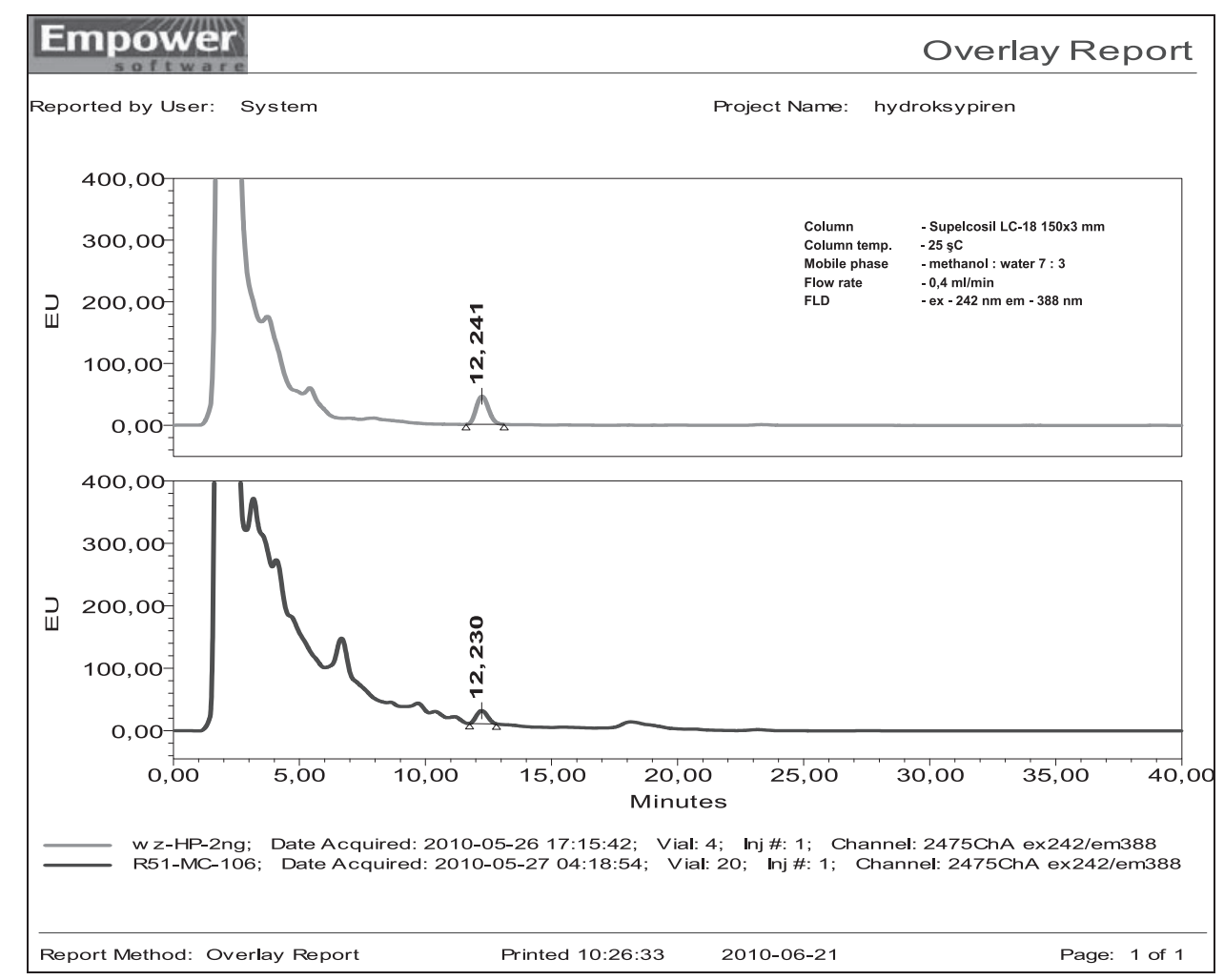

Fig. 1. Example of chromatographic separation of internal standard of 1-HP and analysed urine sample. 


\section{Smoking and ETS exposure}

The smoking status and ETS exposure, was verified by measurement of saliva cotinine level. Saliva was collected three times in pregnancy (once in each trimester). The cotinine level in saliva was analysed by liquid chromatography with tandem mass spectrometry/isotope dilution (LC-MSMS). A $0.25 \mathrm{ml}$ of saliva was extracted with a SPE method on OASIS HLB 96-well Plate and analysed using Alliance High Performance Liquid Chromatograph (Waters) with XTerraC18 MS, $3.5 \mu \mathrm{m}, 150 \times 2.1 \mathrm{~mm}$ column (Waters). Quantitative analysis was made with MRM mode by Quattro Micro API tandem mass spectrometer equipped with electrospray probe (Micromass/Waters). Calibration curve was based on the ratio of native cotinine and deuterium-labelled surrogate (internal standard) peak area. To ensure the highest quality of results, every series of analyses included QC samples such as: repeated samples (already analysed), blank, inhouse reference material and calibration control samples (2 levels of concentrations).

According to the former results of the tobacco smoking exposure study, all women for which cotinine level in saliva was higher than $10 \mathrm{ng} / \mathrm{ml}$ were recognized as smokers.

\section{Statistical analysis}

The geometric mean (GM), geometric standard deviation (GSD) and the range for 1-HP concentration in urine $(\mu \mathrm{g} / \mathrm{g}$ creatinine) was analysed depending on different variables. In the regression analysis, season of urine collection was analysed as categorical variable based on month of monitoring (summer season: May-Aug, and winter season: Sep-April). The women were classified as smokers when their cotinine level in saliva was higher then $10 \mathrm{ng} / \mathrm{ml}$, the others were recognized as nonsmokers. Binary variables were used to capture whether subjects were exposed to road traffic, used coal kitchen stove and used coal house heating. For place of residence we use the categories based on number of inhabitants. Frequency of smoked, grilled, or fried food intake was divided into two categories: < 1 per week, and $\geq 1$ per week. For some part of the women ( 217 women) for whom 1-HP was analysed twice (during second and third trimester of pregnancy) the comparison of the level of this biomarker depending on the week of pregnancy was performed.

All statistically significant variables identified in univariate analysis $(\mathrm{p}<0.05)$ and the coal house heating were included in the multivariate method where the GM ratio was calculated.

\section{RESULTS}

\section{Sociodemographic characteristics}

\section{of the study population}

Table 1 shows the sociodemographic characteristic of the study population. Most of the women, $70 \%$, were in the age category 20-30 years and 27\% of them were older than 30 . About $74 \%$ of the women were married. More than half of the study population had at least 12 years of education and only $13 \%$ of them less than 9 years. High percentage of the women $(85 \%)$ were employed. Slightly more than half of the subjects lived in big cities ( $>500$ thousands of inhabitants) and $19 \%$ of them in cities with 100-500 thousands of inhabitants and $21 \%$ in small ones $(<10$ thousands of inhabitants). Based on cotinine level in saliva, about $20 \%$ of the pregnant women could be identified as smokers. Almost half of the studied population had urine sample collected and analysed (for 1-HP concentration) two times in pregnancy (in second and third trimester), 215 of the women had the analysis performed only for second and 17 only for third trimester. The urine sample was collected mostly in winter season (for $70 \%$ of study sample). Most of the women had reported consumption of smoked, grilled or fried food once per week or more frequently (91\%). About $40 \%$ of study subjects reported road traffic close to their place of residence. Two percent of women used coal kitchen for cooking and $32 \%$ coal for house heating. 
Table 1. Sociodemographic characteristics of the study population ( $\mathrm{N}=449)$

\begin{tabular}{|c|c|c|}
\hline \multirow{2}{*}{ Characteristic } & \multicolumn{2}{|c|}{ Study population } \\
\hline & $\mathrm{n}$ & $\%$ \\
\hline \multicolumn{3}{|l|}{ Age (years) } \\
\hline$\leq 20$ & 16 & 3.6 \\
\hline $20-30$ & 313 & 69.7 \\
\hline$\geq 31$ & 120 & 26.7 \\
\hline \multicolumn{3}{|l|}{ Marital status } \\
\hline married & 333 & 74.2 \\
\hline unmarried & 116 & 25.8 \\
\hline \multicolumn{3}{|l|}{ Maternal education (years) } \\
\hline$<9$ & 59 & 13.1 \\
\hline $9-12$ & 153 & 34.1 \\
\hline$\geq 12$ & 237 & 52.8 \\
\hline \multicolumn{3}{|l|}{ Employment status } \\
\hline unemployed & 67 & 14.9 \\
\hline employed & 382 & 85.1 \\
\hline \multicolumn{3}{|c|}{ Place of residence (inhabitants in thousands, $n$ ) } \\
\hline$>500$ & 254 & 56.6 \\
\hline $100-500$ & 86 & 19.2 \\
\hline 10-100 & 17 & 3.8 \\
\hline$<10$ & 92 & 20.5 \\
\hline \multicolumn{3}{|l|}{ Smoking status } \\
\hline non-smokers (cotinine $\leq 10 \mathrm{ng} / \mathrm{ml}$ ) & 360 & 80.2 \\
\hline smokers (cotinine > $10 \mathrm{ng} / \mathrm{ml}$ ) & 89 & 19.8 \\
\hline \multicolumn{3}{|l|}{ 1-HP in urine sample } \\
\hline second visit only & 215 & 47.9 \\
\hline third visit only & 17 & 3.8 \\
\hline both second and third visit & 217 & 48.3 \\
\hline \multicolumn{3}{|l|}{ Season of urine collection } \\
\hline summer & 136 & 30.3 \\
\hline winter & 313 & 69.7 \\
\hline \multicolumn{3}{|c|}{ Frequency of smoked, grilled, or fried food intake $(\mathrm{N}=253)$} \\
\hline$<1$ per week & 23 & 9.1 \\
\hline$\geq 1$ per week & 230 & 90.9 \\
\hline \multicolumn{3}{|l|}{ Road traffic } \\
\hline no & 268 & 59.7 \\
\hline yes & 181 & 40.3 \\
\hline \multicolumn{3}{|l|}{ Coal kitchen stove $(\mathrm{N}=260)$} \\
\hline no & 254 & 97.7 \\
\hline yes & 6 & 2.3 \\
\hline \multicolumn{3}{|l|}{ Coal house heating $(\mathrm{N}=260)$} \\
\hline no & 176 & 67.7 \\
\hline yes & 84 & 32.3 \\
\hline
\end{tabular}




\section{1-HP concentration in urine of pregnant women}

Mean 1-HP concentration in urine of pregnant women ranged from 0.02 to $10.2 \mu \mathrm{g} / \mathrm{g}$ creatinine with the geometric mean $0.4 \mu \mathrm{g} / \mathrm{g}$ creatinine (GSD $\pm 2.5 \mu \mathrm{g} / \mathrm{g}$ creatinine) (Table 2). In univariate analysis, the frequency of smoked, grilled or fried food intake, subjective perception of road traffic, coal kitchen stove and house heating did not have significant impact on 1-HP concentration $(p>0.05)$. Women who had collected urine sample in summer had significantly higher mean 1-HP concentration in urine than women for whom that collection was performed in winter time (GM: 0.5 vs. $0.3 \mu \mathrm{g} / \mathrm{g}$ creatinine; $\mathrm{p}<0.001)$. Much higher 1-HP concentration was also found among smokers than nonsmokers (GM: 0.7 vs. $0.3 \mu \mathrm{g} / \mathrm{g}$ creatinine; $\mathrm{p}<0.001$ ) and among those who live in big cities ( $>500$ thousands of inhabitants) than in small ones ( $\leq 500$ thousands of inhabitants), (GM: 0.5 vs. $0.3 \mu \mathrm{g} / \mathrm{g}$ creatinine; $\mathrm{p}<0.001$ ). For some part of the study population the urine sample was analysed twice in pregnancy. This comparison did not give statistically significant differences between measurements in second and third trimester $(p=0.7)$.

Table 2. 1-HP concentration in urine of pregnant women

\begin{tabular}{|c|c|c|c|c|c|c|}
\hline \multirow[t]{2}{*}{ Variables } & \multicolumn{3}{|c|}{$\begin{array}{l}\text { 1-HP concentration } \\
\text { ( } \mu \mathrm{g} / \mathrm{g} \text { creatinine })\end{array}$} & \multirow[t]{2}{*}{$\mathrm{p}$} & \multirow[t]{2}{*}{ Sigma $_{\text {within }}$} & \multirow{2}{*}{ Sigma $_{\text {between }}$} \\
\hline & GM & GSD & range & & & \\
\hline Total & 0.4 & 2.5 & $0.02-10.20$ & - & 0.8 & 0.5 \\
\hline \multicolumn{7}{|l|}{ Season of urine collection } \\
\hline summer & 0.5 & 2.4 & $0.04-8.50$ & $<0.001$ & 0.8 & 0.5 \\
\hline winter & 0.3 & 2.5 & $0.02-10.20$ & - & - & - \\
\hline \multicolumn{7}{|l|}{ Smoking status } \\
\hline non-smokers (cotinine $\leq 10 \mathrm{ng} / \mathrm{ml}$ ) & 0.3 & 2.3 & $0.02-10.20$ & $<0.001$ & 0.8 & 0.4 \\
\hline smokers (cotinine $>10 \mathrm{ng} / \mathrm{ml}$ ) & 0.7 & 2.6 & $0.02-8.50$ & - & - & - \\
\hline \multicolumn{7}{|l|}{ Place of residence (inhabitants in thousands, $n$ ) } \\
\hline$>500$ & 0.5 & 2.5 & $0.02-10.20$ & $<0.001$ & 0.8 & 0.4 \\
\hline$\leq 500$ & 0.3 & 2.2 & $0.02-2.40$ & - & - & - \\
\hline \multicolumn{7}{|l|}{ Frequency of intake of smoked, grilled, or fried food } \\
\hline$<1$ per week & 0.3 & 2.3 & $0.04-1.20$ & 0.7 & 0.7 & 0.4 \\
\hline$\geq 1$ per week & 0.3 & 2.2 & $0.02-2.90$ & - & - & - \\
\hline \multicolumn{7}{|l|}{ Road traffic } \\
\hline no & 0.3 & 2.3 & $0.02-2.90$ & 0.3 & 0.7 & 0.4 \\
\hline yes & 0.3 & 2.0 & $0.02-1.30$ & - & - & - \\
\hline \multicolumn{7}{|l|}{ Coal kitchen stove } \\
\hline no & 0.3 & 2.3 & $0.02-2.90$ & 0.4 & 0.7 & 0.4 \\
\hline yes & 0.3 & 1.5 & $0.02-0.70$ & - & - & - \\
\hline \multicolumn{7}{|l|}{ Coal house heating } \\
\hline no & 0.3 & 2.2 & $0.02-2.90$ & 0.3 & 0.7 & 0.4 \\
\hline yes & 0.3 & 2.4 & $0.02-2.10$ & - & - & - \\
\hline \multicolumn{7}{|l|}{ Week of pregnancy at the time of urine collection } \\
\hline second visit (median: 23 weeks of pregnancy) & 0.4 & 2.4 & $0.02-10.20$ & 0.7 & 0.8 & 0.5 \\
\hline third visit (median: 33 weeks of pregnancy) & 0.4 & 2.6 & $0.02-6.70$ & - & - & - \\
\hline
\end{tabular}

GM - geometric mean.

GSD - geometric standard deviation. 


\section{Multivariable adjusted predictors of personal exposure to $\mathrm{PAH}$}

Multivariable analysis confirmed that significantly higher concentration of 1-HP in urine of pregnant women was

Table 3. Multivariable adjusted predictors of personal exposure to $\mathrm{PAH}$ measured by $1-\mathrm{HP}$ concentration in urine of pregnant women

\begin{tabular}{lcc}
\hline \multicolumn{1}{c}{ Variable } & GM ratio & $\mathrm{p}$ \\
\hline Season of urine collection & & \\
$\quad$ summer & 1.1 & 0.010 \\
$\quad$ winter & 1.0 & - \\
Smoking status & & \\
$\quad$ no & 1.0 & $<0.001$ \\
$\quad$ yes & 1.7 & - \\
Place of residence & & \\
(inhabitants in thousands, $\mathrm{n})$ & & \\
$\quad>500$ & 1.3 & 0.001 \\
$\quad \leq 500$ & 1.0 & - \\
Coal house heating & & \\
$\quad$ no & 1.0 & 0.080 \\
$\quad$ yes & 1.2 & - \\
\hline
\end{tabular}

GM - geometric mean.

Sigma $_{\text {between }}=0.192$, Sigma $_{\text {within }}=0.596$.

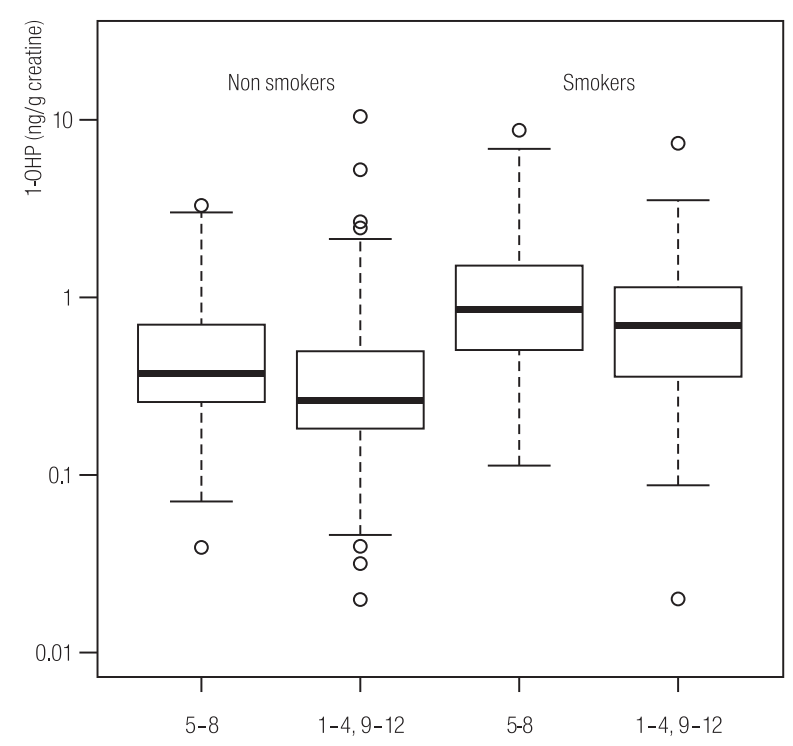

Fig. 2. Association between 1-HP concentration and season of urine collection in smokers and non-smokers. observed for summer collection $(\mathrm{p}=0.01)$ and smokers $(\mathrm{p}<0.001)$ (Table 3). Women living in big cities were significantly more exposed to PAH measured in terms of 1-HP than in small ones $(p=0.001)$. The study participants who used coal for house heating had higher 1-HP concentration than those who did not use this type of heating but the differences were not statistically significant $(p=0.08)$.

Additional analysis performed in smokers and non-smokers indicated that in both groups of women in winter season 1-HP concentration was significantly lower than in summer season (Figure 2).

\section{DISCUSSION}

In the present study the biological monitoring of environmental PAH exposure performed in the group of 449 pregnant women showed that 1-HP concentration in urine ranged from 0.02 to $10.2 \mu \mathrm{g} / \mathrm{g}$ creatinine with the geometric mean $0.4 \mu \mathrm{g} / \mathrm{g}$ creatinine. The significantly higher concentration of 1-HP in urine of pregnant women was observed for summer collection, among smokers and for the women living in big cities. A review of the environmental and occupational studies analysing urinary 1-HP level was performed by Hansen et al. [1]. The authors identified 25 environmental studies covering different sources of exposure (smoking, dietary intake of PAH, seasonal effects, residence in industrial area, traffic pollution, and use of coal and wood for cooking) and different populations (adults, children).

To make the results from our study comparable to other studies, $\mu \mathrm{g} / \mathrm{g}$ creatinine need to be recalculated into $\mu \mathrm{mol} / \mathrm{mol}$ creatinine $(\times 0.518 ; \mathrm{GM}: 0.4 \mu \mathrm{g} / \mathrm{g}$ creatinine is equal to $0.2 \mu \mathrm{mol} / \mathrm{mol}$ creatinine). Based on Hansen et al. analysis, the highest concentrations among adults (GM: $1.5 \mu \mathrm{mol} / \mathrm{mol}$ creatinine, range: $0.26-15.6 \mu \mathrm{mol} / \mathrm{mol}$ ) were observed in Burundi study assessing indoor air exposure in traditional housing using wood burning as the main source of energy [13]. 
In Poland, analysis of 1-HP in urine of pregnant women depending on smoking status was performed in Poznań [14]. The mean concentration of 1-HP in urine among smokers was $0.2 \mu \mathrm{mol} / \mathrm{mol}$ creatinine and among non-smokers $0.1 \mu \mathrm{mol} / \mathrm{mol}$ creatinine. Detailed analysis of exposure to PAH was performed for US and Polish cohorts of pregnant women; however, the analysis of such exposure was based on personal air monitoring or determinations of PAH-DNA adduct levels [8,10]. Personal PAH exposure was much higher in Kraków than in NYC.

To assess PAH exposure in our study, we analysed 1-HP concentration in urine. It would be reasonable to assess also other metabolites of PAH but, unfortunately, that was not feasible in this study.

In the agreement with other studies $[1,8,10]$ also in our analysis higher 1-HP concentration was observed among smokers. Nowadays it is well established that smoking is a major source for PAH exposure in subjects not occupationally exposed to $\mathrm{PAH}$ and it is also accepted that the number of cigarettes smoked correlated rather well with urinary 1-HP concentrations. Well documented smoking status verified by cotinine level in saliva updated several times in pregnancy, which allowed for reliable smoking exposure assessment and analysis using 1-HP level is a major advantage of our study.

The present study, like other findings, also found higher level of 1-HP among residents of big cities compared to those of the smaller ones, which can be explained by higher PAH concentration from road traffic [1]. It would be also advisable to account for the time spend outdoors as the predictor of high PAH exposure; this has not been done in our study and can be regarded as a limitation of our analysis.

Majority of the studies reported that concentrations of most PAH were higher in winter than in summer season. Our findings, however, show that 1-HP concentration was significantly higher in summer than in winter season. One possible explanation for the higher summertime concentration of 1-HP in urine is release of PAH from road surfaces, soil and vegetation which is positively correlated with temperature. In the study by Tonne et al. [7] the concentrations of pyrene precursor of 1-HP measured in summer were significantly higher than those measured in winter, contrary to other PAH components for which the high concentrations were observed in wintertime. Also other findings indicated significantly higher concentrations of low and medium-molecular-weight PAH measured in warmer weather which the authors attributed to PAH release from surfaces with higher temperature $[15,16]$.

Environmental studies indicate that the consumption of a PAH-rich diet (grilled, fried and smoked) and coal heating method can influence the excretion of 1-HP [1]. Some such association, although statistically insignificant, was also observed in our study.

\section{CONCLUSIONS}

The significantly higher concentration of 1-HP in the urine of pregnant women was observed for summer collection, among smokers and those living in big cities.

\section{ACKNOWLEDGEMENTS}

We are grateful to all mothers and children taking part in the Repro_PL study and to the midwives, obstetricians, neonatologists and paediatricians for their cooperation and help in the recruitment and follow-up of the cohort.

\section{REFERENCES}

1. Hansen AM, Mathiesen L, Pedersen M, Knuds LE. Urinary 1-hydroxypyrene (1-HP) in environmental and occupational studies - A review. Int J Hyg Environ Health 2008;211 (5-6):471-503.

2. Scherer G, Richter E. Biomonitoring exposure to environmental tobacco smoke (ETS): a critical reappraisal. Hum Exp Toxicol 1997;16:449-59. 
3. Van Rooij JGM, Veeger MMS, Bodelier-Bade MM, Scheepers, PTJ, Jongeneelen FJ. Smoking and dietary intake of polycyclic aromatic hydrocarbons as sources of interindividual variability in the baseline excretion of 1-hydroxypyrene in urine. Int Arch Occup Environ Health 1994;66:55-65.

4. Vyskocil A, Fiala Z, Fialova D, Krajak V, Viau C. Environmental exposure to polycyclic aromatic hydrocarbons in Czech Republic. Hum Exp Toxicol 1997;16:589-95.

5. Bouchard M, Viau C. Urinary 1-hydroxypyrene as a biomarker of exposure to polycyclic aromatic hydrocarbons: biological monitoring strategies and methodology for determining biological exposure indices for various work environments. Biomarkers 1999;4:159-87.

6. Choi H, Jedrychowski W, Spengler J, Camann DE, Whyatt RM, Rauh V, et al. International studies of prenatal exposure to polycyclic aromatic hydrocarbons and fetal growth. Environ Health Perspect 2006;114(11):1744-50.

7. Tonne C, Whyatt RM, Camann DE, Perera FP, Kinney PL. Predictors of personal polycyclic aromatic hydrocarbon exposures among pregnant minority women in New York City. Environ Health Perspect 2004;112:754-9.

8. Jędrychowski W, Whyatt WM, Camann DE, Bawle UV, Peki K, Spengler JD. Effect of prenatal PAH exposure on birth outcomes and neurocognitive development in a cohort of newborns in Poland. Study design and preliminary ambient data. Int J Occup Med Environ Health 2003;16(1):21-9.

9. Choi H, Perera F, Pac A, Wang L, Flak E, Mroz E, et al. Estimating individual-level exposure to airborne polycyclic aromatic hydrocarbons throughout the gestational period based on personal, indoor, and outdoor monitoring. Environ Health Perspect 2008;116(11):1509-18.

10. Perera F, Tang D, Whyatt R, Lederman SA, Jedrychowski W. DNA damage from polycyclic aromatic hydrocarbons measured by benzo[a]pyrene-DNA adducts in mothers and newborns from Northern Manhattan, The World Trade Center Area, Poland, and China. Cancer Epidemiol Biomarkers Prev 2005;14(3):709-14.

11. Polańska K, Hanke W, Gromadzińska J, Ligocka D, Gulczyńska E, Sobala W, Wąsowicz W. Polish mother and child cohort study - defining the problem, the aim of the study and methodological assumptions. IOMEH 2009;22(4):383-91.

12. Jongeneelen FJ, Anzion RB, Henderson P. Determination of hydroxylated metabolites of polycyclic aromatic hydrocarbons in urine. J Chromatogr 1987;413:227-32

13. Viau C, Hakizimana G, Bouchard M. Indoor exposure to polycyclic aromatic hydrocarbons and carbon monoxide in traditional houses in Burundi. Int Arch Occup Environ Health 2000;73:331-8.

14. Florek W, Piekorzewski W, Kornacka M, Szmatko A. Assessment of exposure of pregnant tobacco smokers to polycyclic aromatic hydrocarbons. Przegl Lek 2005;62(10):1013-18 [in Polish].

15. Dimashki M, Lim L, Harrison R, Harrad S. Temporal trends, temperature dependence, and relative reactivity of atmospheric polycylic aromatic hydrocarbons. Environ Sci Technol 2001;35(11):2264-7.

16. Lioy P, Greenberg A. Factors associated with human exposures to polycyclic aromatic hydrocarbons. Toxicol Ind Health 1990;6(2):209-23.

This work is available in Open Access model and licensed under a Creative Commons Attribution-NonCommercial 3.0 Poland License - http://creativecommons.org/ licenses/by-nc/3.0/pl/deed.en. 